\title{
Assessment the Effective Ground Motion Parameters on Seismic Performance of R/C Buildings using Artificial Neural Network
}

\author{
A. Kia* and S. Sensoy \\ Department of Civil Engineering, EMU, Gazimagusa, Mersin 10, Turkey; \\ ali.kia.cien@gmail.com, serhan.sensoy@emu.edu.tr
}

\begin{abstract}
Building damage level due to earthquake is widely related to the features of the record which consist of many parameters. Although it is difficult to realize the ground motion parameters that have high influence on building performance, the vital parameters that may cause building damage may be considered as PGA, PGV, PGD, PGA/PGV, PGA/PGD, PGV/PGD, frequency content, effective time duration, fault line distance of the earthquake. In this study, these parameters were selected in order to determine more effective parameter on the building performance. For this aim, a model of Artificial Neural Network (ANN) algorithm was used as an efficient tool consisting of the obtained results of nonlinear time history analysis of samples. The 200 records, produced by strike-slip fault mechanism, were selected for the soil type C (Z3) according to the Turkish Earthquake Code [1]. A six story R/C frame building, with three various spans were analyzed via IDARC-2D software. The Park and Ang damage index was used in order to evaluate the vulnerability of buildings. The results showed that the ANN can be able to determine the effective parameters of ground motions with sufficient correlation. Also the most and least significant parameters of earthquake are discussed based on the results of the analysis.
\end{abstract}

Keywords: Artificial Neural Network, Building Damage, Ground Motion Parameters, Nonlinear Time History Analysis, Reinforced Concrete Building

\section{Introduction and Background}

One of the most important objectives of seismology is to identify structural damage indices related to ground-motion parameters. In the recent decade, some earthquake such as Tohoku in Japan (Mw 9.0, 2011), Maule in Chile (Mw 8.8, 2010), and Sumatra in Indonesia ${ }^{2}$ were occurred with various seismic duration. Newmark et al. ${ }^{3}$ used peak ground velocity (PGV), peak ground acceleration (PGA) and peak ground displacement (PGD) in order to draw the elastic response spectra. Extensive research has been conducted on the PGA/PGV ratio, for measure the frequency content of the strong ground motions ${ }^{4}$. In these studies, the best parameters among the various constraints were determined using mathematical function and regression analysis. Riddell and Garcia ${ }^{5}$ used a set of 52 earthquake records, in order to establish the correlation between twenty-three intensity parameters of earthquake and four response variables including hysteretic energy, input energy, elastic and inelastic spectral ordinates. The results showed that no parameter could be singly satisfied over the entire frequency range. Indeed, they found that each ground acceleration, ground velocity and ground displacement indices were occurred in the acceleration sensitive region, velocity sensitive region and displacement-controlled region, respectively. Recently, ANNs were used in many fields of sciences such as engineering, mathematics, physics, medical science and etc. Lautour and Omenzetter ${ }^{6}$ studied thirteen structural and six ground motion parameters in order to predict the seismic structural damage of 2D reinforced concrete frames using ANNs. In that study, an acceptable mapping between the structural and ground motion characteristics (input indices) and the damage values (output index) was established. Caglar et al. ${ }^{7}$ used a multi-layer perceptron (MLP) neural network in

*Author for correspondence 
order to determine the base shear force, fundamental periods, base bending moments and top-floor displacement of 165 reinforced concrete buildings in two directions under Marmara earthquake record. The results demonstrated that the MLP neural network successfully determined the response of buildings under the earthquake. Three methods, global approximation of a deterministic database, local interpolation of database and artificial neural networks were used for evaluation of seismic reliability of a 5 story reinforced concrete building by Moller et al. ${ }^{8}$ The obtained results expressed good agreement between the two applied methods and ANN. For evaluating the damage detection of a railway bridge, a model of simply supported beam with one-span was considered and the obtained values of numerical solution were compared with a MLP neural network 9 . The results showed that the high validity and efficiency of the proposed network.

The propose of this study is to determine the effective ground motion characteristics using ANNs. For this aim, a sample of $2 \mathrm{D}$ reinforced concrete building with six levels was considered and analyzed based on 200 different ground motion records via IDARC-2D V7.0 software and the amount of damages were considered as targets of network. The network was run for nine times and in each time, one of the ground motion parameters was ignored in order to evaluate the sensitivity of network toward the eliminated parameter and finally, the obtained results from the networks were compared together.

\section{Modeling Approach}

\subsection{Sample Frames and Material Properties}

In this study, a $2 \mathrm{D} \mathrm{R} / \mathrm{C}$ frame having6-storieswas considered as a sample of mid-rise frame. For designing the sample, 2007 version of Turkish Earthquake Code ${ }^{1}$ and TS-500 ${ }^{10}$ were used as seismic load and structural components design instructions, respectively. The compressive strength of concrete was considered $21 \mathrm{MPa}$. Also for steel material properties, $3000 \mathrm{MPa}$ and $4000 \mathrm{MPa}$ were selected as yield and ultimate strength of steel, respectively. The properties of soil type III (C) was considered based on TEC $2007^{1}$. Figure 1 depicts the plan view of this model. The properties of the sample frame are shown in Table 1.

\subsection{Damage Identification Index}

In recent years, many researches have been done for evaluating the vulnerability of buildings under seismic excitation and the amount of damages often were calculated based on theoretical definition, mathematical probability and practical tests. These indices commonly used in dimensionless case and are limited between zero for the elastic state (undamaged) and one for collapsed state. Also they can be applied for estimation of the building's imposed damage under the earthquakes and able to prepare the suitable retrofitting plan. In this investigation, Park \&Ang damage index was selected among the improved indices

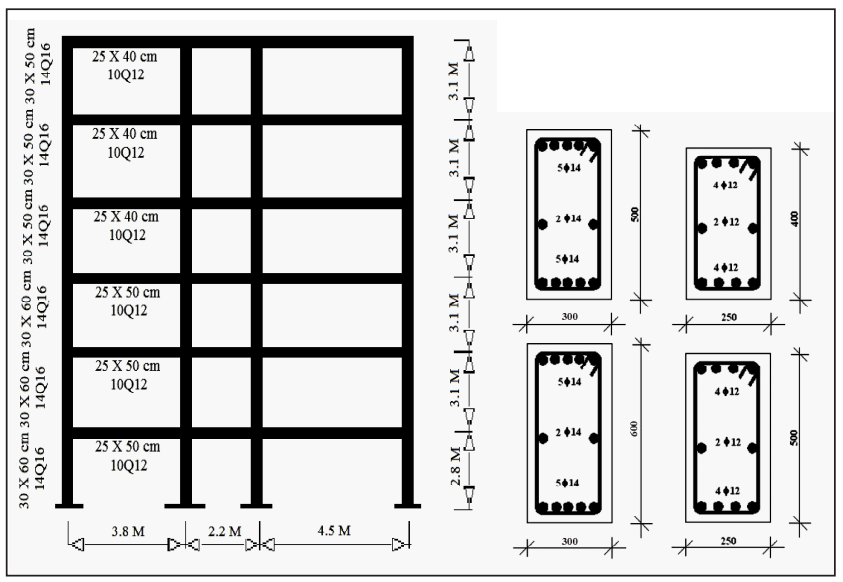

Figure 1. Column and beam's support cross sections and plan view of sample frame.

Table 1. The properties of the sample frame

\begin{tabular}{lccccc}
\hline Mode & Frequency $(\mathrm{Hz})$ & Period (Sec) & $\begin{array}{c}\text { ModalParticipation } \\
\text { Factor }\end{array}$ & $\begin{array}{c}\text { Modal Weight } \\
\text { (Weight Units) }\end{array}$ & $\begin{array}{c}\text { Relative Modal } \\
\text { Weight (\%) }\end{array}$ \\
\hline 1 & 1.76485 & 0.56662 & 0.3234 & 1025.899 & 72.97 \\
2 & 4.47032 & 0.2237 & 0.1523 & 227.621 & 16.19 \\
3 & 8.28723 & 0.12067 & 0.0621 & 37.837 & 2.691 \\
4 & 11.03989 & 0.09058 & 0.0736 & 53.172 & 3.782 \\
5 & 17.31538 & 0.05775 & 0.0699 & 47.968 & 3.412 \\
6 & 23.82126 & 0.04198 & 0.0370 & 13.423 & 0.955 \\
\hline
\end{tabular}


and is defined as the linear combination of the maximum displacement and the dissipated energy ${ }^{11}$. This index is defined by Equation (1).as:

$$
D I=\frac{\delta m}{\delta u}+\frac{\beta}{\delta u \cdot P_{y}} \int d E h
$$

where $\ddot{a}_{\mathrm{m}}$ and $\ddot{a}_{\mathrm{u}}$ are the maximum and ultimate deformation of element under cyclic loading, respectively; $P_{\mathrm{y}}$ is the yield strength of the structure; $\int d E_{\mathrm{h}}$ is the hysteretic energy absorbed by the structural element during the response history; and $\beta$ is a constant parameter.

\section{Effective Ground Motion Parameters}

In order to evaluate the seismic damages of buildings, the characterization of ground motion records are required which is directly affect the analysis and also design of buildings. In the recent decade, selections a set of ground motion indices have been assessed by many researchers to find the most effective parameter on performance of buildings. Probably it is better to use a set of synthetic or real ground motion records which have proper characteristic such as effective time duration, appropriate frequency range, consistency with an intended site and etc. Recorded events have shown that earthquakes with a very large PGA may not cause significant structural damage more than earthquakes with a very low PGA. Indeed, the similar of parameters seem to influence significantly effective on level of structural damage. For example, the ratio of PGV to PGA is indicated by many researchers as being a measure of destructiveness ${ }^{12,13}$. Also the effective duration of earthquake is defined based on the energy of the record. Several measures was employed as the accelerogram's total energy which one of the most important of them is the Arias Intensity (AI) ${ }^{14}$ is expressed by Equation 2 as:

$$
A I=\frac{\pi}{2 g} \int_{0}^{T r} a(t) d t
$$

Where $a(t)$ is the acceleration history over time, $\operatorname{Tr}$ is the total recorded time of the accelerogram and $g$ is the acceleration due to gravity. Then the significant time duration is employed as the interval between the 5-95\% of $\mathrm{AI}^{15,16}$.

The relation of AI shows that the energy accumulates of the longer duration for a ground motion is more than the shorter duration of its. In this investigation, nine indices include; PGA, PGV, PGD, PGA/PGV, PGA/PGD, PGV/PGD, frequency content, effective time and fault line distance were selected in order to determine more and least effective parameters on the buildings damages. For dynamic analysis of structure, 200 ground motion records with various moment magnitudes $(5.2 \leq \mathrm{M} \leq 8.3)$ and different source-to-site distances, site class $\mathrm{C}$ and strike-slip fault mechanism were selected from the Pacific Earthquake Engineering Research Center (PEER) ${ }^{17}$. In Figure 2 (a), the distribution of frequency content for the records is shown. Furthermore, the ranges of ground motion parameters are provided in Table 2. Also the proportion between PGA and effective time duration of records are shown in Figure 2(b). The relationship between site epicentral distances versus moment magnitude and 5-95\% time duration are shown in Figure 2(c) and Figure 2(d), respectively.

\section{Artificial Neural Network}

Artificial neural network (ANN) is an intelligent method which is developed in analogy using a proper modeling of neurons in the human brain. The method defines the mathematical functions that lead to simulate the behavior of intracellular of brain neurons. The connections between neurons are established using the neuronal weights which their performances are similar to the synapses in natural neurons. In recent century, ANNs were used in many fields of sciences such as engineering, mathematics, medical sciences, etc., for prediction, function approximation, clustering and classification of data and etc. In this investigation, a MLP neural network was used to determine the effective parameters of ground motions. In this network, all data was normalized between zero and one, then were shuffled and divided into three parts, i.e. 70 percent of total data for training process, 15 percent for validating process and 15 percent for testing process.

\subsection{Data Generation, Training and Testing of ANN}

For generation of data, a sample of six story frame were considered and analyzed under 200 ground motion records and the amount of damage were obtained based on Park \&Ang damage index. Then all data were normalized using linear normalization method in order to change the range of data between zero and one. Finally, the data were shuffled and divided to three parts, $70 \%$ of all data for training process, $15 \%$ for validating process and remained $15 \%$ for testing process. For finding the 


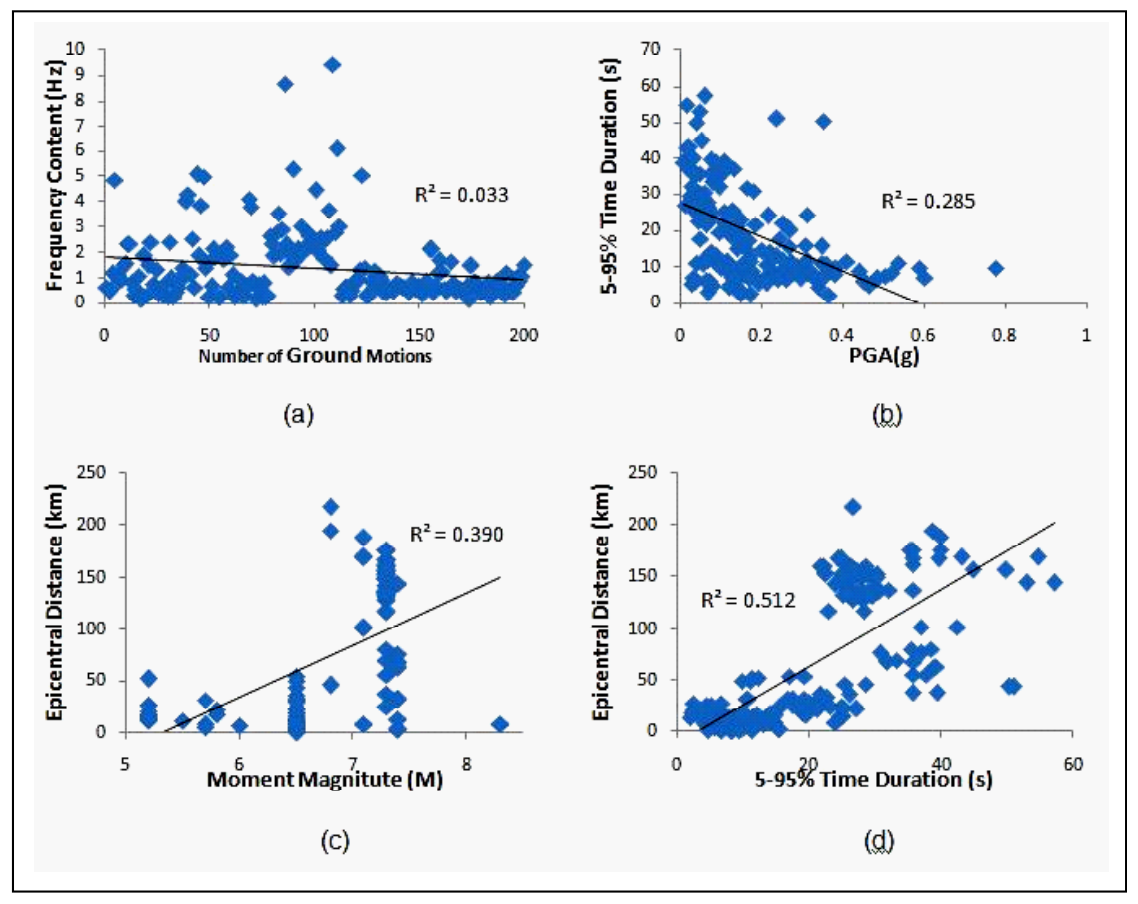

Figure 2(a). The frequency content values of records, 2(b). The effective time duration versus PGA, 2(c). The epicentral distance values versus moment magnitude and $2(\mathrm{~d})$. The epicenteral distance values versus the effective time duration.

Table 2. The ranges of ground motion parameters

\begin{tabular}{lll}
\hline Parameters & \multicolumn{1}{c}{ Definition } & Range of parameters \\
\hline PGA & $\begin{array}{l}\text { Peak Ground } \\
\text { Acceleration }(\mathrm{g})\end{array}$ & $0.01-0.775$ \\
PGV & $\begin{array}{l}\text { Peak Ground } \\
\text { Velocity (cm/s) }\end{array}$ & $1.1-109.8$ \\
& Peak Ground & \\
PGD & Displacement (cm) & $0.12-65.89$ \\
PGA/PGV & Ratio of PGA to PGV & $0.002155-0.029773$ \\
PGA/PGD & Ratio of PGA to PGD & $0.00211-0.558333$ \\
PGV/PGD & Ratio of PGV to PGD & $0.761548-20$ \\
F.C & $\begin{array}{l}\text { Frequency } \\
\text { Content (Hz) }\end{array}$ & $0.146-9.4238$ \\
T.D & $\begin{array}{l}\text { 5-95\% Time } \\
\text { Duration (s) }\end{array}$ & $1.98-57.17$ \\
E.D & $\begin{array}{l}\text { Epicentral } \\
\text { Distance (km) }\end{array}$ & $0.5-217.4$ \\
\hline
\end{tabular}

best fit of each data set, root mean square error (RMSE), mean square error (MSE) and correlation coefficient (R) were applied. These parameters are expressed as:

$$
R M S E=\sqrt{\frac{\sum_{i=1}^{n}\left(\left(X_{p r e}-X_{\text {val }}\right)\right)^{2}}{n}}
$$

where $X_{p r e}$ is predicted value, $X_{v a l}$ is actual value and $n$ is number of data.

$$
\begin{gathered}
M S E=R M S E^{2} \\
R=\frac{\sum_{i=1}^{n}\left(X_{i}-\bar{X}\right) *\left(Y_{i}-\bar{Y}\right)}{\sqrt{\sum_{i=1}^{n}\left(X_{i}-\bar{X}\right)^{2} * \sum_{i=1}^{\prime}\left(Y_{1}-\bar{Y}\right)^{2}}}
\end{gathered}
$$

where $X_{i}$ is actual value, $\bar{X}$ is mean of actual values, $Y_{i}$ is predicted value, $\bar{Y}$ is mean of predicted values and $n$ is number of data.

\subsection{Numerical Results}

In this step, the network was trained based on all input data that are represented by nine neurons in input layer, optimum neurons in hidden layer and a neuron in output layer. The number of neurons in hidden layer was determined based on try-and-error. Therefore twenty neurons were employed for this layer with tansig activation function. In training process, the network stopped at 19 iterations with gradient and MSE equal to 0.01871 and 0.00583 , respectively. Also the best validation performance was 0.05820 and occurred at epoch 13 . The values of RMSE, MSE, R, mean $(\mu)$ and standard deviation $(\sigma)$ of errors are presented in Table 3. 
Table 3. The RMSE, MSE, $R, \mu$ and $\sigma$ values for each set of data

\begin{tabular}{lcccc}
\hline & Train Data & Validation Data & Test Data & All Data \\
\hline RMSE & 0.10920 & 0.24123 & 0.35997 & 0.19108 \\
MSE & 0.01192 & 0.05820 & 0.12958 & 0.03651 \\
$\mathrm{R}$ & 0.94892 & 0.81771 & 0.66528 & 0.85220 \\
$\mu$ & -0.01521 & 0.04780 & -0.02412 & -0.00709 \\
ó & 0.10852 & 0.24049 & 0.36530 & 0.19143 \\
\hline
\end{tabular}
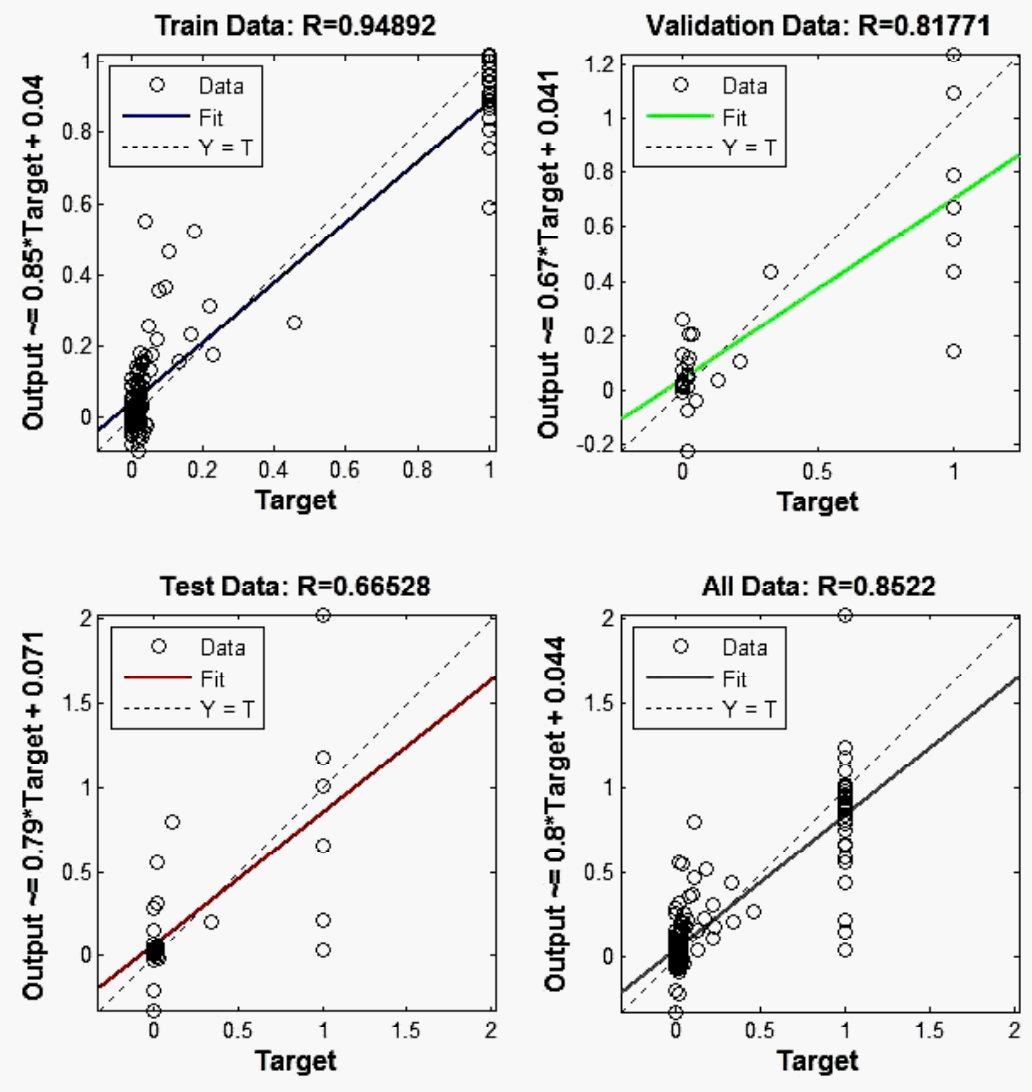

Figure 3. The regression and fit function for each set of data

The Figure 3 shows that the fitting function and regression for train, validation, test and all data.

In order to find the effective parameters of ground motion, the training process of network was repeated for nine times and in each time, one of the ground motion parameters was eliminated. Therefore, the number of neurons in input layer was reduced to eight. The results of this process are shown in Table 4.

Based on extracted results (see Table 4), the minimum values of R were obtained for PGA/PGV, frequency content, $\mathrm{PGV} / \mathrm{PGD}$ and PGV cases, respectively which is expressed the network was sensitive to these parameters. Therefore the network was run based on these four parameters as input data (four neurons in input layer), ten hidden layer neurons (optimum neurons) and a neuron in output layer. In training process, the network stopped at 25 iterations with gradient and MSE equal to 0.00431 and 0.0332 , respectively. Also the best validation performance was 0.01136 and occurred at epoch 19. The values of RMSE, MSE, R, mean $(\mu)$ and standard deviation (ó) of errors are presented in Table 5. Moreover, Figure 4 shows that the fitting function and regression for train, validation, test and all data. 
Table 4. The RMSE, MSE, R, $\mu$ and $\sigma$ values for all data

\begin{tabular}{lccccc}
\hline Eliminated Parameter & RMSE & MSE & R & $\mu$ & ó \\
\hline PGA & 0.19337 & 0.03739 & 0.84401 & 0.00379 & 0.19382 \\
PGV & 0.23130 & 0.05350 & 0.80124 & -0.08361 & 0.21620 \\
PGD & 0.20957 & 0.04392 & 0.82806 & -0.01935 & 0.20920 \\
PGA/PGV & 0.23459 & 0.05503 & 0.77255 & -0.01081 & 0.23493 \\
PGA/PGD & 0.21979 & 0.04831 & 0.82541 & 0.05024 & 0.21450 \\
PGV/PGD & 0.22133 & 0.04899 & 0.79408 & 0.01137 & 0.22159 \\
Frequency Content & 0.24655 & 0.06079 & 0.79006 & -0.10129 & 0.22535 \\
Effective Time Duration & 0.19903 & 0.03961 & 0.83377 & 0.00186 & 0.19952 \\
Fault line Distance & 0.19532 & 0.03815 & 0.84128 & -0.01292 & 0.19538 \\
\hline
\end{tabular}

Table 5. The RMSE, MSE, R, $\mu$ and $\sigma$ values for each set of data

\begin{tabular}{lcccc}
\hline & Train Data & Validation Data & Test Data & All Data \\
\hline RMSE & 0.18401 & 0.10659 & 0.27995 & 0.19277 \\
MSE & 0.03386 & 0.01136 & 0.07837 & 0.037161 \\
$\mathrm{R}$ & 0.87230 & 0.90892 & 0.65085 & 0.84514 \\
$\mu$ & -0.00065 & 0.000099 & -0.02014 & -0.00346 \\
ó & 0.18467 & 0.10841 & 0.28400 & 0.19323 \\
\hline
\end{tabular}

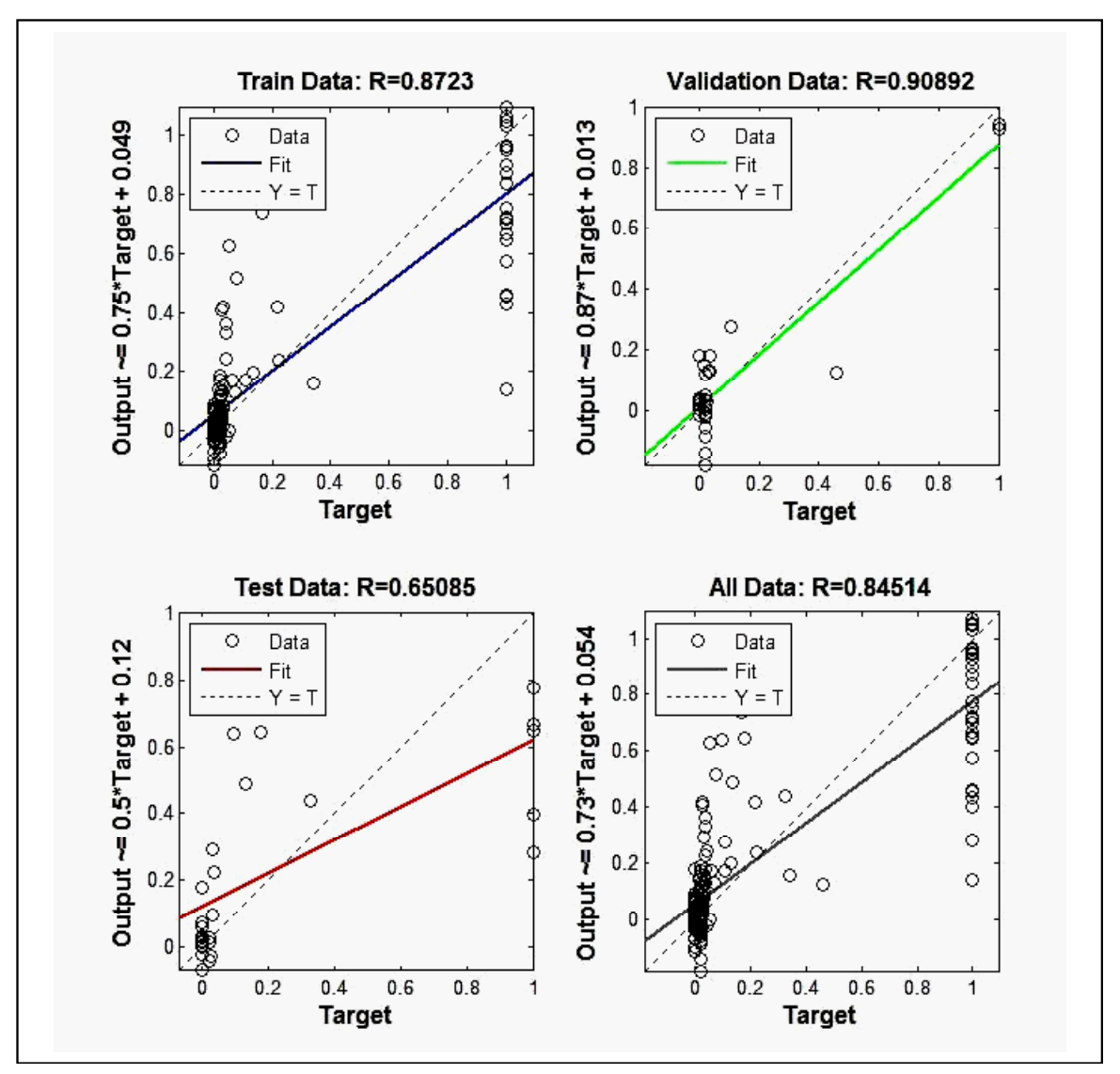

Figure 4. The regression and fit function for each set of data. 


\section{Conclusion}

In this study the effective ground motion parameters were identified based on ANNs. For this aim, a six story frame was considered and analyzed under 200 different ground motion records which were selected due to the soil type C (Z3) and the amounts of imposed damages were calculated as an identification index. The observed result from ANNs showed that the minimum values of $\mathrm{R}$ were obtained for PGA/PGV, frequency content, PGV/ PGD and PGV cases, respectively which is indicated that the network is sensitive to these parameters. Moreover, the ineffective parameters consist of PGA, fault line distance, effective time duration, PGA/PGD and PGD, respectively. Also it should be considered that because the sample frame was in intermediate period region, the velocity controlled responses is more effective among the earthquake parameters. The amount of obtained $\mathrm{R}$ from two networks consist all input data (nine parameters) and four sensitive data (four parameters) were obtained equal to 0.85220 and 0.84514 , respectively which is shown that around $0.8 \%$ difference between them. Therefore for buildings in this period range, it is suggested to use the above effective parameters which are sufficiently enough for evaluation of vulnerability instead of considering more ground motion characteristics.

\section{References}

1. Turkish Earthquake Code. Regulations on structures constructed in disaster regions. Ministry of Public Works and Settlement. 2007.

2. United States Geological Survey. Scientific agency of the United States government. 2014

3 Newmark NM, Blume AJ, Kapur KK. Seismic design spectra for nuclear power plants. Journal of the Power Division. 1973; 99:287-303.
4. Tso WK, Zhu JT, Heidebrecht CA. Engineering implication of ground motion A/V ratios. Soil Dynamic Earthquake ngineering. 1992; 11:133-44.

5. Riddell R, Garcia JE. Hysteretic energy spectrum and damage control. Earthquake Engineering and Structural Dynamics. 2001; 30:1791-816.

6. Lautour RO, Omenzetter P. Prediction of seismic-induced structural damage using artificial neural networks. Engineering Structures. 2009; 31:600-6.

7. Caglar N, Elmas M, Yama, DZ, Saribiyik M. Neural networks in 3-dimensional dynamic analysis of reinforced concrete buildings. Construction and Building Materials. 2008; 22:788-800.

8. Moller O, Foschi OR, Rubinstein M, Quiroz L. Seismic structural reliability using different nonlinear dynamic response surface approximations. Structural Safety. 2009; 31:432-42.

9. model. Engineering Structures. 2013; 52:408-21.

10. Turkish Standards Institute. Building code requirements for reinforced concrete. Ankara, Turkey. 2000.

11. Park JY, Ang SHA, Wen KY. Seismic Damage Analysis of Reinforced Concrete Buildings. Journal of structure Engineering. 1985; 111:740-57.

12. Zhu TJ, Tso WK, Heidebrecht AC. Effect of peak ground $\mathrm{a} / \mathrm{v}$ ratio on structural damage. Journal of Structural Engineering. 1988; 114:1019-37.

13. Meskouris K, Kratzig WB, Hanskotter U. Seismic motion damage potential for R/C wall-stiffened buildings, Elsevier Applied Science.1992; 125-36.

14. Arias A. A measure of earthquake intensity in seismic design of nuclear power plants. Cambridge, MA: MIT Press; 1970. p. $438-68$.

15. Trifunac MD, Brady AG. A study on the duration of strong earthquake ground motion. Bulletin of the Seismological Society of America. 1975; 65:581-626.

16. FoschaarJC,BakerJW,Deierlein GG.PreliminaryAssessment of Ground Motion Duration Effects on Structural Collapse. Proceedings of the 15th World Conference on Earthquake Engineering; 2012; Lisbon, Portugal.

17. Pacific Earthquake Engineering Research Center. PEER NGA Database. 2014. 